\title{
Positive Psychotherapy with a Pulse: Achieving Depth through Dialogue
}

\author{
Matthew Pugh ${ }^{1}$ (10) Caroline Salter ${ }^{2}$
}

Accepted: 28 October 2020 / Published online: 23 November 2020

(C) Springer Nature Switzerland AG 2020

\begin{abstract}
The majority of psychotherapeutic approaches work on the basis that addressing what is "wrong" with individuals will facilitate recovery. Positive therapies adopt a different approach, demonstrating that adaptive change can be achieved by addressing wellbeing and what is "right". Unfortunately, research indicates the effectiveness of positive psychotherapeutic interventions is sometimes suboptimal, perhaps due to their reliance on written and talk-based strategies. Drawing on evidence from leading theories of cognition (e.g. Interacting Cognitive Subsystems and Dual Representation theories), the present paper suggests that therapeutic effects positive interventions might be augmented through greater use of experiential methods, namely 'chairwork'. The practice-focused paper sets out the PPIs in their current form and describes how chairwork could be applied in these areas of well-being, including gratitude, personal strengths, forgiveness, benefit-finding, and existential meaning. Research is needed to establish the efficacy of experiential PPIs and to determine whether are advantageous compared to traditional positive interventions.
\end{abstract}

Keywords Chairwork $\cdot$ Experiential $\cdot$ Positive psychology $\cdot$ Positive psychotherapy $\cdot$ Roleplay

\section{Introduction}

A common assumption of psychotherapy has been that elucidating what is 'wrong' with individuals will somehow promote functioning and recovery. Positive psychotherapeutic interventions (PPIs) take the opposite approach, recognising the human

Matthew Pugh

matthewpugh@nhs.net

1 Vincent Square Eating Disorders Service, Central and North West London NHS Foundation Trust, 1 Nightingale Place, London SW10 9NG, UK

2 Adult Psychology and Psychotherapy Department, Central and North West London NHS

Foundation Trust, London, UK 
tendency to naturally orientate towards negatives (Baumeister et al. 2001). PPIs argue that if clinicians are to counter this bias, treatments should instead focus on what is 'right' with individuals, communities and institutions, alongside promoting the skills, characteristics, and reflectivity necessary for these to flourish (Rashid et al. 2015).

\subsection{Positive Interventions and Positive Psychotherapies}

PPIs encourage individuals to recognise the good in their lives in order to enhance wellbeing and protect against mental and physical ill-health. Accordingly, PPIs seek to ameliorate suffering by increasing positive emotion, engagement, and meaning, rather than targeting suffering per se (Rashid and Seligman 2018a). In practice, PPIs utilise concrete, teachable strategies to promote flourishing, while at the same time acknowledging that, in some situations, 'negative' emotions may be more adaptive than 'positive' ones. In this way, PPIs do not seek to dismiss or deny distress, but instead give equal weight to both strengths and struggles.

First operationalised in the 1990s, PPIs have attempted to enhance positive thoughts, feelings, and behaviours using a range of therapeutic methods, including mindfulness, reminiscence, expressive writing, imagery, and cognitive restructuring. PPIs have also targeted processes related to well-being, including hopefulness, thankfulness, and resourcefulness. Parks and Schueller (2014) have recently identified six 'core' areas of positive intervention: gratitude (appreciation for positive events); forgiveness (replacing resentments with positive feelings towards offenders); savouring (mindful attendance to positive events); strengths (identifying and developing personal resources); meaning (ascribing coherence and significance to one's existence); and empathy (cultivating affiliative, other-orientated emotional responses). Novel areas for positive intervention have also emerged, including creativity, courage, and curiosity (Lopez and Snyder 2009).

In an attempt to consolidate multiple positive interventions within a broader treatment framework, a smaller number of positive therapies (PTs) have developed. Positive psychotherapy (Rashid and Seligman 2018b) represents one such approach. Positive psychotherapy is divided into three phases of treatment: developing a balanced narrative by exploring personal strengths from multiple perspectives; building positive emotions and dealing with adverse intrapersonal events that sabotage efforts to do differently; and consolidating positive relationships and meaning in life. Key foci for positive psychotherapy include wisdom, forgiveness, gratitude, hope, and mindfulness. Other leading evidence-based PTs include hope therapy (Cheavens et al. 2006), wellbeing therapy (Fava et al. 1998), solution-focused brief therapy (de Shazer and Dolan 2007), and Fordyce's happiness programme (Fordyce 1977).

\subsubsection{Evidence-Base}

Research supports the principles of positive psychology. Positive emotions predict therapeutic change (Fitzpatrick and Stalikas 2008) and experiencing more positive emotions enhances relationships, productivity, and health, as well as alleviating distress (Rashid 2009). In addition, personal strengths buffer against the effects of negative life events (Huta and Hawley 2010), counteract the effects of negative emotion (Fredrickson 2001), promote well-being (Fredrickson and Joiner 2002), and facilitate flourishing (Fredrickson 2009). 
PPIs informed by these findings have proven effective (Bolier et al. 2013; Sin and Lyubomirsky 2009). For example, meta-analyses indicate that strengths-focused interventions have the dual effect of increasing positive affect and decreasing depression (Schutte and Malouff 2019), while gratitude-focused interventions generate significant increases in psychological well-being (Davis et al. 2016). PPIs have also produced positive outcomes in the context of specific psychopathologies: gratitude appears to counter the effects of depression (Wood et al. 2008), while hope acts as a change mechanism in the treatment of post-traumatic stress disorder (PTSD; Gilman et al. 2012). Regarding treatment packages, positive psychotherapy has been applied to a range of conditions, including depression (Csillik et al. 2012), alcohol use (Akhtar and Boniwell 2010), borderline personality disorder (Uliaszek et al. 2016), PTSD (Gilman et al. 2012) and psychosis (Meyer et al. 2012; Schrank et al. 2016).

\section{2 "Show, don't tell": An Action-Based Approach to Positive Psychotherapy}

PTs and their constituent PPIs represent a promising step towards alleviating suffering and promoting growth, without the need to focus on suffering directly. However, it remains unclear exactly how PPIs achieve therapeutic effects (Rashid 2009). Additionally, research indicates that responses to PTs are not always satisfactory: remission rates of $64 \%$ are reported (Seligman 2006), while some comparison studies have found no observable differences between positive interventions and control groups (e.g. Mongrain and Anselmo-Matthews 2012). Furthermore, the therapeutic effects of some PPIs appear to be relatively small (White et al. 2019), vulnerable to decay over time (Emmons and McCullough 2003; Seligman et al. 2005), and unrelated to individuals' quality of life (Helgeson et al. 2006). Taken together, these findings indicate that there is a need to enhance the benefits of PTs and PPIs.

One explanation for the limits of PPIs relates to the strategies used to bring about change. Except for a small number of imagery-based approaches (e.g. Bryant et al.'s 2005 positive reminiscence imagery), the vast majority of PPIs rely on written or talkbased interventions. Accordingly, there is, perhaps, a risk that "we [the positive therapist and patient] talk about it and talk about it, and nothing is accomplished" (Perls 1969, p.36). Cognitive science indicates that discussion alone is often insufficient to modify the cognitive-affective structures underlying emotional distress and cultivate those which support well-being (Epstein 2014; Teasdale 1997). In addition, theories of experiential learning (Kolb 1984) and information processing (Tangden and Borders 2017) highlight the importance of learning through multisensorial experience in order to enhance the acquisition, storage, retrieval, and elaboration of new knowledge. Therefore, while the aims of PTs and PPIs are both valid and vital, the mediums used to stimulate change may be limited.

\subsubsection{Theoretical Perspectives on Cognitive-Affective Change}

Noted previously, negative emotions tend to be stronger, more pervasive, and longerlasting than their positive counterparts (Rashid 2009). In their dual representation theory, Brewin et al. (2010) emphasise the need for novel and adaptive mental representations (thoughts, memories, emotional experiences) which 'out-compete' existing (maladaptive) representations. In order for preferential retrieval, these new 
representations must be sufficiently salient, distinctive, and memorable (Brewin 2006). Accordingly, it seems plausible to hypothesise that PPIs in their current form are not sufficiently memorable or evocative to counter negative cognitive-affective content or generate enduring positivity.

Other theories of cognitive-affective science provide further insights. According to the theory of interacting cognitive subsystems (ICS; Teasdale 1993), informationprocessing is governed by two subsystems. The propositional subsystem deals with the processing of factual, language-correspondent information ('analytic processing'), but is unrelated to emotional processes. These meanings equate to "knowing with one's head". In contrast, the implicational code shares direct links with emotion and is influenced by multisensory inputs, including physiological changes and visual stimuli ('holistic processing'). Meanings at this level are synonymous with "knowing with one's heart" and tend to be experienced as non-verbal "felt senses". A growing body of research now suggests that talk-based intervention tends to generate changes at an intellectual (i.e. propositional) level, but not at an emotional (i.e. implicational) level (Bennett-Levy 2003). Consequently, improvements in well-being tend to be limited and relatively short-lived.

Exploring the implications of these two theories, we come to the possibility that, in order to enhance the effects of PPIs, we should look to active therapeutic methods that best enable individuals to 'know', 'feel', 'remember', and 'act' positively. In doing so, PPIs are more likely to bring about modifications at an emotionally meaningful level and, as a result, establish cognitive-affective changes which are sufficiently compelling to contend with the negative biases of human thinking and behaviour.

\subsection{Chairwork}

Consistent with the aforementioned theories, clinicians have increasingly recognised the therapeutic value of experiential interventions. Imagery, behavioural experimentation, and 'chairwork' are now regarded as being amongst the most powerful of therapeutic methods; an assertion which is supported by a growing body of research (Bennett-Levy 2003; Blackwell 2018; Elliott et al. 2013; Giacomucci and Marquit 2020; Orkibi and Feniger-Schaal 2019; Pugh 2019a).

Of these interventions, chairwork has experienced notable attention within positive psychology during recent years (Atkinson and Kirsner 2019; Orkibi 2019; Pugh 2019a; Tomasulo 2018; Tomasolu 2019). Originally conceived within the psychodrama approach almost one century ago (Moreno 1987) and later promoted within gestalt therapy (Perls 1969), modern chairwork represents a collection of 'common' experiential methods which are applied in a variety of psychotherapeutic orientations (Pugh and Bell in press). These interventions aim to facilitate transformative, here-and-now interactions with parts of the self (including internalised representations of others) using chairs, their positioning, movement, and dialogue. In terms of typology, chairwork is differentiated into those tasks which seek to facilitate exchanges of information between parts of the self ('horizontal procedures') and those which aim to establish decentred awareness of the mind ('vertical procedures') (Pugh and Broome 2020). Key horizontal procedures include 'interviews' with the client in the role of self-parts, other persons, and personifications; 'dialogues' between two or more parts of the self; concretising, measuring, and mapping self-parts and events using chair-based 
'depictions'; and enacting scenes from the client's past or potential future through 'dramatisations' (see Kellogg 2019; Kipper 1986; Pugh and Bell in press). Key vertical procedures relate to self-distanced, 'dispassionate witnessing' of the mind versus carefocused 'compassionate witnessing' (Table 1). Quantitative studies have confirmed the effectiveness of chairwork, demonstrating that these methods can improve mood, enhance self-compassion, and resolve interpersonal difficulties such as complicated grief. Furthermore, qualitative analyses have highlighted the intensity, memorability, and realism of these techniques (see Pugh 2019a for a review).

Despite growing appreciation, chairwork is often seen as enigmatic. Moreover, many clinicians doubt their ability to apply experiential techniques effectively (Owen-Pugh and Symons 2013). Taking contemporary cognitive-affective theory as our springboard, and encouraged by the growing interest in chairwork amongst positive therapists, we now present a selection of practice-friendly chairwork techniques for enhancing aspects of well-being. These include personal strengths, gratitude, forgiveness, post-traumatic growth, and existential meaning. We hope that these ideas and illustrations will not only serve to enhance the quality of PPIs, but also inspire new directions in practice and research.

\section{2 'Positive’ Chairwork Interventions}

\subsection{Gratitude}

Gratitude interventions have been shown to enhance psychological well-being and reduce emotional distress (Davis et al. 2016; Wood et al. 2010). Relevant exercises include gratitude journaling (Emmons and McCullough 2003), list-making (Seligman et al. 2005), and the preparation of letters which may or may not be delivered to benefactors ('gratitude visits'; Seligman et al. 2006).

Enactive procedures have been identified as a valuable medium for generating, expressing, and experiencing gratitude (Froh et al. 2014; Pugh 2019a). For example, Tomasolu (2019) has described empty-chair dialogues for facilitating 'gratitude

Table 1 Common Forms of Chairwork

\begin{tabular}{ll}
\hline Horizontal procedures & Description \\
\hline $\begin{array}{l}\text { Interviews } \\
\text { Dialogues }\end{array}$ & $\begin{array}{l}\text { Questioning the client in the role of self-parts, other persons, or personifications } \\
\text { Encounters and conversations between self-parts, other persons, or } \\
\text { personifications } \\
\text { Enacting scenes from the past or future }\end{array}$ \\
$\begin{array}{l}\text { Dramatisations } \\
\text { Depictions }\end{array}$ & $\begin{array}{l}\text { Representational mapping and measurement using chairs } \\
\text { Disclosures }\end{array}$ \\
$\begin{array}{l}\text { Vertical procedures } \\
\text { Compassionate } \\
\text { Witnessing }\end{array}$ & Compassionate observation of self-parts and task engagement \\
Dispassionate Witnessing & Self-distanced observation of self-parts and task engagement \\
\hline
\end{tabular}


dialogues' or 'virtual gratitude visits'. This procedure is particularly useful in situations where benefactors are unavailable, inaccessible, or do not take physical forms (e.g. divine powers). Gratitude dialogues begin with the client imagining the benefactor in an empty seat (Therapist: "Imagine your departed grandfather were here, in this empty seat. [Introduces an empty chair]. How do you see him? What is it like being in his company again?") and then delivering their message of gratitude (Therapist: "Would you like to share your gratitude letter with him? What would you like him to know?"). Next, the client reverses roles by changing seats to experience receiving gratitude (Therapist: "Speaking as your grandfather, what have you heard Matthew share with you? [Gestures to the client's former seat]. How do you respond to hearing his gratitude? Is there anything you would like him to know?").

It is not unusual for individuals to have mixed feelings towards recipients of gratitude; thankfulness is sometimes accompanied by resentment, envy, or grief (Rashid and Seligman 2018b). Moreover, individuals are often better able to share appreciations once 'negative' emotions have been expressed. Two-chair gratitude dialogues enable clients to voice, validate, and process these conflicting feelings. A triangular ' $V$ ' formation of chairs is used in this exercise (Kellogg 2017). As with the empty-chair approach, two-chair gratitude dialogues begin with the client imagining the 'other' in an empty seat; if this presence stirs negative emotions, these are stated from chair one. Once expressed, the client then changes seats and conveys their gratitude (and any other positive emotions) from chair two.

Surprisingly few self-referential gratitude interventions are presented in the positive psychology literature. Appreciation dialogues (Dayton 1994; Pugh 2019b) allow individuals to experience receiving gratitude from others. To begin, the client identifies an individual whom they believe is appreciative of their existence. Changing seats and adopting the perspective of this 'other', the client then conveys these appreciations to their former chair (Therapist: "Matthew, I'd like you to change seats and step into the shoes of your spouse, Natalie. [Client changes seats]. Natalie, I understand you feel grateful for the support Matthew has provided you over the years. [Gestures to the client's former seat]. Can you tell him what you are thankful for? What do you value about him?"). In order to counteract the human tendency to undermine positive qualities (Padesky 1990), the appreciative other is asked how they would respond to their positive feedback being discounted (Therapist: "Natalie, you may be aware that Matthew often dismisses his positive qualities. What would you say to him about that? [Gestures to the empty seat]. What would you like him to do with the gratitudes you've shared?").

\subsection{Best Versions of the Self}

The best possible self (BPS) is a well-known PPI which involves writing about, drawing, or visualising the best version of one's self (King 2001; Owens and Patterson 2013; Rashid and Seligman 2018a). Research indicates that BPS interventions are associated with a variety of benefits, including improved mood, optimism, and well-being (Loveday et al. 2018).

Embodied approaches to the BPS have the advantage of not only anchoring positive experiences of the self to physiological states (Bell et al. 2019) but also creating opportunities to dialogue with one's BPS. Embodiment begins with the client changing 
seats and adopting the outward characteristics of their BPS, including its posture (e.g. upright, grounded), facial expression (e.g. relaxed, half-smiling), tone of voice (e.g. clear, measured), and rate of breathing (e.g. calm, smooth). Next, inward characteristics of the BPS are brought to mind, such as courage (e.g. a willingness to face difficulties), wisdom (e.g. the ability to see events from different perspectives), acceptance (e.g. that pain is an unavoidable part of life), and compassion (e.g. the desire to relieve suffering) (Gilbert 2010). Experiencing the BPS is deepened in several ways. These include kinaesthetic exercises (e.g. inviting the client to move and interact with the therapy space as their BPS), dialoguing with the therapist as the BPS (Therapist: "It's nice to meet you, best possible self. How are you thinking and feeling right now?"), and inviting the client to dialogue with their experiencing self from the perspective of the BPS (Therapist: "Speaking as the BPS, what guidance you can you offer Caroline? [Gestures to the client's original seat]. What would you like her to understand about herself and the dilemma she is facing?").

\subsection{Strengths}

Strengths refer to personal resources which buffer against life stressors and support the attainment of desired outcomes (Brownlee et al. 2013; Macaskill and Denovan 2014). Strengths-focused interventions aim to bolster personal resources through their identification, application, and optimisation, typically using a combination of assessment, feedback, and self-reflection (e.g. journaling and expressive writing) (Louis and Lopez 2014; Rashid and Seligman 2018a).

Helping individuals identify character strengths is a central feature of many experiential therapies which incorporate chairwork, including psychodrama and the therapeutic spiral model (Giacomucci 2018; Hudgins 2019). Another method, voice dialogue (Stone and Stone 1989) enables individuals to appreciate and cultivate their strengths through a process of 'intrapersonal interviewing' (Pugh 2019a). This procedure involves the client changing seats and 'speaking as' their character strength. The therapist then proceeds to understand the strength through interview (see Table 2) (Therapist: "I'd like you to change seats and speak as your courageous side. [Client switches chairs]. It's nice to meet you, Courage. Tell me about your role in Matthew's life"). Areas for discussion with strengths include their developmental origins (Therapist: "Where do you come from, Courage? When did you first come into Matthew's life?"), operation (Therapist: "How do you maintain Matthew's courage? What strategies do you use?"), and multisensory qualities (Therapist: "If I could see you, how would you appear?"). Exploring how the strength might apply itself to issues or dilemmas the client is facing is also productive (Therapist: "As you know, Courage, Matthew feels pretty anxious about giving a presentation next week. [Gestures to the client's empty seat]. How could you help him out with that? What advice would you give him?").

Drawing upon the principles of strength-based cognitive behavioural therapy (Padesky and Mooney 2012), strength-focused dialogues aim to elucidate strengthbased strategies and explore how they might be applied in novel areas (Pugh 2019a). This procedure begins with the identification of a personal strength and the client adopting its perspective in a second chair (Therapist: "Imagine that this chair represents the humour you bring to being a parent. [Gestures to an empty seat]. Change 
Table 2 Prompts for interviews with character strengths

Nice to meet you, [name of character strength]. Tell me about your self...

- When did you come into this individual's life?

- Do you take after anyone they know or have known?

- In what situations do you come out? Do you get to come out a lot?

- How do help this individual?

- Does this individual recognise what you do for him/her?

- What would happen if you weren't a part of this individual's life?

- How would this individual's life change if you were around more?

- Are there particular situations where you'd like to be around more?

- If you could change something in this individual's life, what would that be?

- Is there anything you'd like from this individual?

- Is there any advice you would like to give him/her?

- If I could see you, what would you look like?

- What would you like to be called?

chairs and be the humorous side of your self'). After moving seats, the client then identifies and elaborates 'resilience strategies' associated with this strength (Therapist: "As a new father, I imagine that you sometimes encounter challenges. Speaking as your humorous side, how do you maintain this when problems arise? What techniques do you use?"). Next, the client stands (bringing power to the strength) and explores how this resource might apply itself to life domains and issues, represented by additional chairs (Therapist: "Imagine this seat represents your plans to return to university. [Introduces an empty chair]. Looking at this goal from the vantage point of your humour, how could this strength help you realise this ambition? What humourrelated strategies could you employ?").

\subsection{Forgiving Others}

Forgiveness is associated with multiple dimensions of well-being and improvements in mental health (Akhtar and Barlow 2018). Deciding to forgive others typically involves a combination of tasks including recalling the transgression, reflective exploration, and costs-benefits analysis of forgiveness. Two-chair decisional balancing provides a more evocative means to evaluate the advantages and disadvantages of granting forgiveness (Engle and Arkowitz 2008; Pugh and Salter 2018). Beginning with the side that feels strongest, the client presents their reasons for granting forgiveness in chair one and against forgiveness in chair two. As the client shuttles between these chairs, responding and counter-responding from each perspective, conflicting attitudes towards forgiveness gradually become less polarised and more integrated. However, some clients may need to vent anger at misdeeds before contemplating forgiveness. In this case, emptychair dialogues with the offender enable the release of these hurts and resentments (Pugh 2019a).

Forgiveness also requires empathy for offenders, enabling the victim to see transgressions as more understandable and potentially unintentional (Wade and Worthington Jnr. 2005). Of course, cultivating empathy for wrongdoers is not always ethical or appropriate, and should only be pursued collaboratively. Role reversal has been described as the empathy intervention par excellence (Yaniv 2012) and is centralised in many empathy training programmes (Teding van Berkhout 
and Malouff 2016). Role reversal begins with the client changing seats and adopting the point-of-view of the offender. To facilitate this shift in perspective, the therapist begins by 'interviewing' the client in their new role (Blatner and Blatner 1991) (Therapist: "Speaking as the individual who betrayed you - what is your name? How old are you? How long have you known Caroline? What was your relationship like before this conflict?'). Once immersed in the antagonist's role, role-play moves on to explore the offence. Drawing upon Worthington's (Worthington Jr. 2006) guidance, Pugh (2019a) suggests that five areas are productive to discuss during forgivenessorientated role reversals: 1). situational pressures which influenced the offender's actions, 2). past experiences which contributed to committing the offence, 3). aspects of the offender's personality which influenced their (in)actions, 4). ways in which the victim may have (inadvertently) provoked the offence, and 5). whether the offender's (in)actions had any benign intent.

Committing to forgiveness plays an equally vital role in letting go of past hurts (Wade and Worthington Jnr. 2005). Inspired by redecision therapy (Goulding and Goulding 1979), decision dialogues invite the client to make a declaration about their forgiveness to the perpetrator in fantasy, who is represented by an empty chair. While the form and content of decision dialogues should be of the client's making, these statements of commitment typically include a). a description of the transgression ('recall'), b). how the transgression affected the client ('impact'), c). a statement of forgiveness and the reasons for this ('decision'), and $\mathrm{d}$ ). how forgiveness will be integrated into daily life ('implementation'). These commitments to forgiveness are made public not only by the therapist's presence during chairwork, but also through the inclusion of imaginal 'witnesses' who are represented by additional seats. For other examples of chairwork applied to forgiveness, readers are referred to the psychodrama literature (see Giacomucci 2018; Hudgins 2019).

\subsection{Self-Forgiveness}

Fewer studies have explored the process of self-forgiveness compared to interpersonal forgiveness. Forgiveness of the self is defined as a positive attitudinal shift involving the abandonment of self-resentment and self-contempt, coupled with the restoration of self-respect, acceptance, and compassion (Enright 1996; Hall and Fincham 2005). Left unchecked, the refusal to forgive oneself can generate considerable shame, self-criticism, and destructive behaviour (Tangey et al. 2005).

Moral injuries refer to violations of deeply held moral beliefs, resulting in guilt and resistance to self-forgiveness (Litz et al. 2009; Shay 2011). Originally developed for the treatment of veterans, adaptive disclosure (Litz et al. 2016) invites the client to share the burden of their transgression with either the victim or a moral authority through the medium of chairwork or imagery. Chair-based adaptive disclosure begins with the client imaging the 'other' (i.e. the victim or moral authority) in an empty chair. Next, the client describes their transgression and its personal consequences (Therapist: "Tell him/her about the offence and the ways it has affected your life and relationships"); at this point, the therapist highlights the client's suffering and remorse associated with the offence (Therapist: "Describe the guilt / sadness you have carried since this event occurred"). Third, the client imagines how the 'other' responds to this disclosure (Therapist: "What does (s)he say in response to what you have shared?"); here, the 
therapist deepens forgiveness-related themes emerging during the disclosure (Therapist: "Notice that (s)he understands that it wasn't your fault and wants you to move on"). The client may choose to ask for forgiveness towards the end of this dialogue (Therapist: "Would you like to ask him/her if (s)he forgives you? How does (s)he respond?"). Chairwork closes by saying goodbye to the other and thorough debriefing.

\subsection{Moving on from Past Hurts}

Letting go of lingering distress is a feature of many PTs (e.g. Greenberg et al. 2010; Magyar-Moe 2014; Rashid and Seligman 2018a; Worthington Jr. et al. 2014). Despite short-term increases in distress, research indicates that processing and moving on from troubling events provides several benefits, including improved physical health, facilitating meaning-making, and enhancing self-compassion (Greenberg and Pascual-Leone 2006; Pennebaker and Smyth 2016; Whelton 2004).

Positive psychology has favoured writing or 'emotional storytelling' to process distressing life events and bring closure (Magyar-Moe 2014; Pennebaker and Smyth 2016). In contrast, emotional processing through chairwork involves recounting and revising narratives about events in a second seat (Kellogg 2019; Polster 1987). For example, the client might move to chair two and describe the troubling event(s), 'shake off' this initial disclosure by walking around the room, and tell the story again with more detail, emotional depth, or from a different perspective. Highly distressing stories are approached in a graded manner, beginning with factual third-person descriptions (i.e. self-distanced storytelling or the 'mirror' position in psychodrama) (Therapist: "Describe your assault through the eyes of an observer - what happened when Matthew was attacked?") and ending with evocative first-person accounts (i.e. selfimmersed storytelling) (Therapist: "Now, tell me the story of your assault through your own eyes, as if you were there again") (Dayton 1994; Yardely-Matwiejczuk 1997). Recounting events from a second chair confers two important benefits. First, it concretises the idea that these stories relate to just one aspect of experience and do not define the self. Secondly, representing events with a second seat also lays the foundations for two-chair dialogues between the experiencing self (chair one) and the trauma or 'traumatised self' (chair two).

An alternative approach, multiple selves (Gilbert 2009) invites the client to explore troubling events from the perspective of key affective states held in different chairs (i.e. the 'Anxious Self', 'Sad Self', and 'Angry Self') (Therapist: "Let's begin by exploring your experience of your wife's death from the perspective of 'Sad Self' - change seats and speak as that part of your self'). Key aspects of each self are then elaborated, including somatic components (Therapist: "When you think about your wife's passing, where do you notice 'Sad Self in your body?"), thoughts (Therapist: "What does 'Sad Self want to say about this loss?"), motivations (Therapist: "If 'Sad Self were in complete control, what would it want to do?"), and their underlying needs (Therapist: "What does 'Sad Self need in order to settle?"). Multiple selves dialogues usually conclude with the client responding to each self from a compassionate perspective (Therapist: "Looking at these emotions from the seat of your 'Compassionate Self', how do you feel towards them? In what ways do they make sense? What could you say to each self to bring them care and closure?") (Kolts 2016). Alternatively, these emotional experiences are witnessed by asking the client to stand and decentre (Therapist: 
"With acceptance and great appreciation for these selves, stand up and notice how each 'Self presents itself in its respective seat'). In this way, the multiple selves exercise serves to not only process and move on from difficult emotional reactions, but also demonstrates that these responses are comprehensible and tolerable (Tobyn Bell, personal communication).

\subsection{Post-Traumatic Growth}

Identifying aspects of personal growth following traumatic events is associated with well-being and improved mood (Helgeson et al. 2006). To facilitate this process of 'benefit finding', many PTs incorporate a combination of psychoeducation, storytelling, expressive writing, self-disclosure, and cognitive interventions (Rashid and Seligman 2018a; Tedeschi et al. 2018; Tennen and Affleck 2002).

Psychodramatic timelines (Dayton 2016; Wells 2018) provide a powerful medium for revisiting past traumas and identifying post-traumatic gains. This enactment involves the client walking an imaginary line representing the years of their life and describing key events. At points of strife (and, relatedly, resiliency), the client crosses over the line and speaks as their past self, recounting personal adversities in the present tense (Therapist: "Be Matthew at 14 years of age - what's happening in your life right now?"). The client then reverses roles by crossing back over the line and responds to their past self (Therapist: "Now be adult Matthew - what do you want to say to your younger self? Tell him about how things are going to change. What gifts will this experience bring him in time?'). Through this process of dialogue and role reversal, psychodramatic timelines provide individuals with an opportunity to soothe lingering pain, highlight aspects of personal growth, and demarcate points of resiliency.

Three-chair dialogues are an alternative method for processing challenging life events and identifying post-traumatic gains. A triangular formation of seats is used. Chairwork begins with the client 'telling the story' of the trauma in chair one (Kellogg 2019). Moving to chair two, the client then describes losses associated with the trauma, which are validated (Therapist: "From this chair, speak about the doors which have closed in your life as a result of this experience"). Having acknowledged these negative consequences, clients are often better able to recognise the positive effects of adversity in chair three (Therapist: "From this third chair, can you see any doors which have opened for you since this event? What have you gained?"). This procedure can be made more evocative by inviting the client to describe personal losses (chair one) and gains (chair two) directly to the traumatic event, represented by an empty seat (chair three) (Therapist: "Imagine your cancer is held in this seat. [Gestures to the empty chair]. Tell it about the ways it has caused you to suffer. [Client speaks]. Now, change seats and tell cancer about the gifts this suffering has brought you").

\subsection{Reappraisal}

Cognitive restructuring techniques such as 'disputation' and 'logical analysis' are utilised in many PTs (Magyar-Moe 2014). These interventions aim to correct the dysfunctional thoughts which generate distressing emotions such as pessimism (Frisch 2006; Seligman 2002) and those which interrupt periods of well-being (Fava 2016). Drawing upon the principles of CBT, cognitive reappraisal typically involves 
the identification, reevaluation, and reality testing of clients' negative automatic thoughts (Beck 1976).

Preliminary research suggests that enactive approaches to cognitive reappraisal structuring are sometimes more effective than pen-and-paper interventions such as automatic thought recording (see Pugh 2019b). Three-chair cognitive restructuring (Pugh 2019a) takes place in three stages. First, the client moves to chair two and presents their negative cognitions in the second-person (Therapist: "Speaking as your pessimistic thoughts, tell Caroline [gestures to chair two] why her work will amount to nothing"). Next, the client returns to their original chair and explores their affective reactions to these cognitions (Therapist: "Change seats. [Client returns to chair one]. How do you feel hearing those thoughts?"). Finally, the client moves to chair three and presents rebuttals to their negative thoughts (Therapist: "Switch seats so that we can hear from your healthy, optimistic side. [Client moves to chair three]. What does this side say in response to those negative thoughts? Tell the pessimistic side [gesturing to chair two] why your work will amount to something"). Should the client become 'stuck' during disputation, chairwork is paused so the therapist can coach. Alternatively, the therapist 'doubles' for the client by presenting counter-evidence on their behalf.

A more evocative approach to enactive reappraisal, the 'devil's advocate' technique (Goldfried et al. 1978) involves the client defending their healthy thoughts in chair one while the therapist challenges these in chair two (Therapist: "I'm going to change seats and enact your pessimistic internal voice. When I present reasons why your work will amount to nothing, I'd like you to refute these statements as passionately as you can"). As with three-chair cognitive restructuring, dialogues are paused if the client is unable to develop counter-arguments. In order to avoid negative projections from the client during this dialogue, the therapist should explain at the outset that they are adopting a role (Therapist: "I'd like to make it clear that when I speak as your pessimistic voice, I am not agreeing with what is said - I am just playing a role") and de-role thoroughly afterwards.

\subsection{Wisdom}

Wisdom - defined as exceptional insight into life and the human condition (Stange and Kunzmann 2008) - is amongst the most prized of human characteristics. Complex and multidimensional, wisdom is believed to integrate several factors including cognition (e.g. expert knowledge), affect (tolerance and compassion), and reflection (flexible perspective-taking) (Ardelt 2003; Kunzmann and Baltes 2005). Wise reasoning refers to a pragmatic style of thinking which incorporates the aforementioned features of wisdom (Kross and Grossmann 2012). Fundamental to wise reasoning is the ability to transcend egocentric viewpoints. For example, research indicates that individuals display greater wisdom when they reflect on problems from a self-distanced perspective (e.g. difficulties experienced by other persons) compared to a self-immersed perspective (Grossmann and Kross 2014).

Chairwork provides an ideal medium for facilitating decentred reasoning. For example, clients might be asked to reason about personal issues as if they belonged to another individual (held in an empty chair) or to solicit the advice of an older, wiser version of their self (Pugh 2019a) (Therapist: "Change seats be Matthew as if 20 years have passed. [Client moves to a new chair]. Speaking with the wisdom that comes with 
age and experience, what guidance would you offer Matthew about his marriage?"). ${ }^{1}$ Public, cultural-historical, and religious icons who embody wisdom-related characteristics ('wisdom exemplars') offer an additional resource for stimulating wise reasoning (Grossmann 2017). Imaginal surveys (Pugh 2019b) involve the client embodying any number of these individuals in different chairs. Wise reasoning is then facilitated by 'interviewing' the client in these fantasy roles (Therapist: [Speaking to the client]. "Doctor Seligman, in what ways do you think Matthew [gestures to the client's original chair] could deepen his sense of purpose in life?"). Alternatively, clients can speak directly to these wise exemplars via two-chair dialogues (Therapist: "Matthew, if you could put one question to Doctor Seligman, what would it be? [Client changes seats and embodies the 'other']. Doctor Seligman, how do you respond to Matthew's query?").

\subsection{Meaning}

Meaningful living has multiple elements, including cognitive factors (e.g. the significance ascribed to one's life), motivational factors (e.g. engaging in values-consistent actions), and affective factors (e.g. the satisfaction accompanying a meaningful life) (Wong 1998). Meaning-orientated interventions appear to enhance well-being (Vos 2016) and have focused on issues related to existential acceptance, the exploration of meaning, and values-driven behaviour (Wong 2012).

Regarding existential acceptance, many individuals are troubled by idealised versions of lives. Dialoguing with one's 'perfect life' invites the client to let go of these imagined realities. This enactment involves the client visualising and then dialoguing with their ideal existence as if it were held in an empty seat (chair two) (Therapist: "Imagine that 'perfect Caroline' is held in this chair. [Gestures to chair two]. What do you see? Describe what her life is like. Is there anything you want to say to her?"). Next, the client reorientates and speaks with their actual existence in chair three. By drawing distinctions between imagined and real life, individuals are encouraged to grieve for 'perfect' existences, relinquish these fantasies, and proceed with embracing reality (Dayton 1994).

'Describing your funeral' and 'epitaph writing' are well-known exercises for clarifying and concretising values-driven living (Hayes et al. 1999; Yalom 1980). A more evocative approach involves the client enacting attendees at their funeral who are interviewed by the therapist (Therapist: "How will you remember the deceased? What stood out most about this individual and their life?"). This is compared against contrasting role-plays in which the client enacts the preferred responses of significant others. In a similar vein, clients might enact their ideal deathbed scene to establish which pursuits have contributed most to their existence (Therapist: "As you approach the end of your life, what have been its most meaningful aspects? What's mattered most to you? If you could go back in time, what advice would you offer your younger self?"). Variations on this theme include interviewing the client in the role of their deceased self (Therapist: "Speaking as deceased Matthew, if you could go back and change your life in one way, what would that be?"), two-chair dialogues between the client's deceased self and a higher power (Therapist: "Change seats and be God-speaking as God, ask

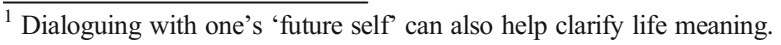


Matthew about how he has lived his life and whether he would do things differently... Now change seats and respond as Matthew"), and two-chair dialogues between the client's current self and deceased self (Blatner 1996; Knittel 2009).

\section{Discussion}

Dialogical interventions represent a promising direction for positive psychology and psychotherapy. Despite having a strong theoretical basis and growing empirical support, experiential procedures are seldom utilised in PTs. However, we must also stress that, in advocating the use of chairwork, we are not implying that traditional PPIs should be abandoned; rather, it is hoped that the present paper demonstrates how chairwork might augment current practice and maximise the efficacy of PPIs. In addition, dialogical interventions such as chairwork might go some way towards circumvent the limitations of existent PPIs, including client illiteracy and the challenge of translating positive cognitive-affective change into sustained behavioural adjustments.

In summary, the main thrust of this paper has been that - consistent with cognitiveaffective theory - enactive, dialogical procedures may be an advantageous medium for cultivating positive emotion and enhancing well-being. Other experiential psychotherapeutic methods also hold promise. For example, research suggests that positive mental imagery stimulates optimism (Meevissen et al. 2011), while adjustments in motor processes (e.g. posture and gait) exert both positive and negative effects upon emotional processes (e.g. Michalak et al. 2014). Creativity itself is beginning to gain momentum as a target and tool for PPIs, with research suggesting that creative activities promote well-being (Richards 2010) and increase openness to experience (e.g. Fleeson et al. 2002). Together, these findings point towards the potential value of a 'multimodal' approach to flourishing, which incorporates cognitive, behavioural, affective, embodied, and experiential interventions (Pugh 2019a).

As with any technique, chairwork is not without its limitations. Firstly, chairwork has an emerging but relatively limited evidence base. Secondly, there are practical considerations to chairwork, including space limitations, availability of chairs, and client mobility. Preliminary guidance regarding how chairwork is adapted in remote tele-therapy has recently been provided (Pugh and Bell 2020; Pugh and Bell in press). Thirdly, we must be thoughtful about whom we offer chairwork: individuals who struggle with emotional regulation may find enactive procedures challenging, thus necessitating some adjustments in their implementation (see Pos and Greenberg 2012). Equally, individuals who are over-regulated may feel compromised by evocative procedures. In order to preserve the therapeutic relationship and avoid harm, clinicians must ensure that chair-based techniques are approached collaboratively and remain within the limits of clients' capacities.

Several important directions for future research are apparent. These include the following:

- Are dialogical PPIs clinically effective, for which clients, and how do they perform relative to existent PPIs?

- What makes dialogical PPIs effective? For example, do their 'active ingredients' relate to emotional involvement, level of immersion, or length of enactment? 
- How do dialogical PPIs compare to other immersive, experiential techniques such as imagery?

- Can positive dialogical interventions be utilised in a self-directed manner, or do they rely on clinician facilitation?

- Are there any risks associated with the use of chairwork within the context of PTs?

In conclusion, chairwork represents a promising addition to the positive therapist's toolkit. As the evidence base for both PPIs and PTs continues to grow, it will be exciting to explore when, how, and for whom chairwork augments their effects.

Financial Support None.

\section{Compliance with Ethical Standards}

Conflict of Interest The first author receives royalties from a textbook which is related to the subject of this paper.

\section{References}

Akhtar, M., \& Boniwell, I. (2010). Applying positive psychology to alcohol-misusing adolescents: A group intervention. Groupwork, 20, 6-31.

Akhtar, S., \& Barlow, J. (2018). Forgiveness therapy for the promotion of mental well-being: A systemic review and meta-analysis. Trauma, Violence, and Abuse, 19, 107-122.

Ardelt, M. (2003). Empirical assessment of a three-dimensional wisdom scale. Research on Aging, 25, 275324.

Atkinson, P., \& Kirsner, N. (2019). Positive psychology and psychodrama. In A. Blatner (Ed.), Action explorations: Using psychodramatic methods in non-therapeutic settings (pp. 315-332). Seattle: Parallax Publications.

Baumeister, R. F., Bratslavsky, E., Finkenauer, C., \& Vohs, K. D. (2001). Bad is stronger than good. Rev Gen Psychol, 5, 323-370.

Beck, A. T. (1976). Cognitive therapy and the anxiety disorders. London: Penguin.

Bell, T., Montague, E., Elander, J., \& Gilbert, P. (2019). "A definite feel-it moment": Embodiment, externalization and emotion during chair-work in compassion-focused therapy. Couns Psychother Res, $20,143-153$.

Bennett-Levy, J. (2003). Mechanisms of change in cognitive therapy: A case of automatic thought records and behavioural experiments. Behav Cogn Psychother, 31, 261-277.

Blackwell, S. E. (2018). Mental imagery: From basic research to clinical practice. J Psychother Integr, 29, $235-247$.

Blatner, A. (1996). Acting-in: Practical applications of Psychodramatic methods (3rd ed.). New York: Springer.

Blatner, A., \& Blatner, A. (1991). Imaginative interviews: A psychodramatic warm-up for developing roleplaying skills. Journal of Group Psychotherapy, Psychodrama and Sociometry, 44, 115-120.

Bolier, L., Haverman, M., Westerhof, G. J., Riper, H., Smit, F., \& Bohlmeijer, E. (2013). Positive psychology interventions: A meta-analysis of randomized controlled studies. BMC Public Health, 13, 1-20.

Brewin, C. (2006). Understanding cognitive behaviour therapy. A retrieval competition account. Behav Res Ther, 44, 765-784.

Brewin, C. R., Gregory, J. D., Lipton, M., \& Burgess, N. (2010). Intrusive images in psychological disorders: Characteristics, neural mechanisms, and treatment implications. Psychol Rev, 117, 210-232.

Brownlee, K., Rawana, J., Franks, J., Harper, J., Bajwa, J., O’Brien, E., \& Clarkson, A. (2013). A systematic review of strengths and resilience literature relevant to children and adolescents. Child Adolesc Soc Work $J, 30,435-459$.

Bryant, F. B., Smart, C. M., \& King, S. P. (2005). Using the past to enhance the present: Boosting happiness through positive reminiscence. J Happiness Stud, 6, 227-260. 
Cheavens, J. S., Feldman, D. B., Gum, A., Michael, S. T., \& Snyder, C. R. (2006). Hope therapy in a community sample: A pilot investigation. Soc Indic Res, 77, 61-78.

Csillik, A., Aguerre, C., \& Bay, M. (2012). Psychothérapie positive de la dépression: Spécificités et apports cliniques. Ann Med Psychol, 170, 541-546.

Davis, D. E., Choe, E., Meyers, J., Wade, N., Varjas, K., Gifford, A., \& Worthington Jr., E. L. (2016). Thankful for the little things: A meta-analysis of gratitude interventions. J Couns Psychol, 63, 20-31.

Dayton, T. (1994). The Drama within: Psychodrama and experiential therapy. Deerfield Beach: Health Communications.

Dayton, T. (2016). Neuropsychodrama in the treatment of relational trauma: Relational trauma repair - an experiential model for treating posttraumatic stress disorder. The Journal of Psychodrama, Sociometry, and Group Psychodrama, 64, 41-50.

de Shazer, S., \& Dolan, Y. (2007). More than miracles: The state of the art of solution-focused brief therapy. New York: Haworth Press.

Elliott, R., Watson, J., Greenberg, L. S., Timulak, L., \& Freire, E. (2013). Research on humanistic-experiential psychotherapies. In M. J. Lambert (Ed.), Bergin \& Garfield's Handbook of Psychotherapy and Behavior Change (6th ed., pp. 495-538). New York: Wiley.

Emmons, R. A., \& McCullough, M. E. (2003). Counting blessings versus burdens: An experimental investigation of gratitude and subjective well-being in daily life. J Pers Soc Psychol, 84, 377-389.

Engle, D., \& Arkowitz, H. (2008). Viewing resistance as ambivalence: Integrative strategies for working with resistant ambivalence. J Humanist Psychol, 48, 389-412.

Enright, R. D. (1996). Counseling within the forgiveness triad: On forgiving, receiving forgiveness, and selfforgiveness. Couns Values, 40, 107-127.

Epstein, S. (2014). A cognitive theory of personality. Oxford: Oxford University Press.

Fava, G. A. (2016). Well-being therapy: Current indications and emerging perspectives. Psychother Psychosom, 85, 136-145.

Fava, G. A., Rafanelli, C., Cazzaro, M., Conti, S., \& Grandi, S. (1998). Well-being therapy: A novel psychotherapeutic model for residual symptoms of affective disorders. Psychol Med, 28, 475-480.

Fitzpatrick, M. R., \& Stalikas, A. (2008). Positive emotions as generators of therapeutic change. J Psychother Integr, 18, 137-154.

Fleeson, W., Malanos, A. B., \& Achille, N. M. (2002). An intra-individual process approach to the relationship between extraversion and positive affect: Is acting extraverted as "good" as being extraverted? J Pers Soc Psychol, 83, 1409-1422.

Fordyce, M. W. (1977). Development of a program to increase personal happiness. J Couns Psychol, 24, 511521.

Fredrickson, B. L. (2001). The role of positive emotions in positive psychology: The broaden-and-build theory of positive emotions. Am Psychol, 56, 218-226.

Fredrickson, B. L. (2009). Positivity: Groundbreaking research reveals how to embrace the hidden strength of positive emotions, overcome negativity, and thrive. New York: Crown Publishing.

Fredrickson, B. L., \& Joiner, T. (2002). Positive emotions trigger upward spirals toward emotional well-being. Psychol Sci, 13, 172-175.

Frisch, M. B. (2006). Quality of life therapy: Applying a life satisfaction approach to positive psychology and cognitive therapy. New York: John Wiley and Sons.

Froh, J. J., Bono, G., Fan, J., Emmons, R. A., Henderson, K., Harris, C., \& Wood, A. M. (2014). Nice thinking! An educational intervention that teaches children to think gratefully. Sch Psychol Rev, 43, 132152.

Giacomucci, S. (2018). The trauma survivor's inner role atom: A clinical map for post-traumatic growth. Journal of Psychodrama, Sociometry, and Group Psychotherapy, 66, 115-129.

Giacomucci, S., \& Marquit, J. (2020). The effectiveness of trauma-focused psychodrama in the treatment of PTSD in inpatient substance abuse treatment. Front Psychol, 11, 1-12.

Gilbert, P. (2009). Overcoming depression: A self-help guide using cognitive Behavioural techniques. London: Robinson.

Gilbert, P. (2010). Compassion focused therapy: Distinctive features. Hove: Routledge.

Gilman, R., Schumm, J. A., \& Chard, K. M. (2012). Hope as a change mechanism in the treatment of posttraumatic stress disorder. Psychol Trauma Theory Res Pract Policy, 4, 270-277.

Goldfried, M. R., Linehan, M. M., \& Smith, J. L. (1978). Reduction of test anxiety through cognitive restructuring. J Consult Clin Psychol, 46, 32-39.

Goulding, M. M., \& Goulding, R. L. (1979). Changing lives through Redecision therapy. New York: Brunner/ Mazel. 
Greenberg, L. S., \& Pascual-Leone, A. (2006). Emotion in psychotherapy: A practice-friendly research review. J Clin Psychol, 62, 611-630.

Greenberg, L. S., Warwar, S., \& Malcolm, W. (2010). Differential effects of emotion-focused therapy in facilitating forgiveness and letting go of emotional difficulties. J Marital Fam Ther, 20, 213-231.

Grossmann, I. (2017). Wisdom and how to cultivate it. Eur Psychol, 22, 233-246.

Grossmann, I., \& Kross, E. (2014). Exploring Solomon's paradox: Self-distancing eliminates the self-other asymmetry in wise reasoning about close relationships in younger and older adults. Psychol Sci, 25, 1571-1580.

Hall, J. H., \& Fincham, F. D. (2005). Self-forgiveness: The stepchild of forgiveness research. J Soc Clin Psychol, 24, 621-637.

Hayes, S. C., Strosahl, K. D., \& Wilson, K. G. (1999). Acceptance and commitment therapy: An experiential approach to behavior change. New York: Guilford Press.

Helgeson, V. S., Reynolds, K. A., \& Tomich, P. L. (2006). A meta-analytic review of benefit finding and growth. J Consult Clin Psychol, 74, 797-816.

Hudgins, K. (2019). Psychodrama revisited: Through the lens of the internal role map of the therapeutic spiral model to promote post-traumatic growth. Zeitschrift für Psychodrama und Soziometrie, 18, 59-74.

Huta, V., \& Hawley, L. (2010). Psychological strengths and cognitive vulnerabilities: Are they two ends of the same continuum or do they have independent relationships with well-being and ill-being? J Happiness Stud, 11, 71-93.

Kellogg, S. (2017). Transformational chairwork two: Complex emotions, trauma and the inner critic. London: Workshop.

Kellogg, S. (2019). Transformational chairwork: Therapeutic change using the four dialogues. InPsych, 41, $16-21$.

King, L. A. (2001). The health benefits of writing about life goals. Personal Soc Psychol Bull, 27, $798-807$.

Kipper, D. A. (1986). Psychotherapy through clinical role playing. New York: Brunner/Mazel.

Knittel, M. G. (2009). Counselling and Drama: Psychodrama a Deux. Bloomington: Xlibris.

Kolb, D. A. (1984). Experiential learning: Experience as the source of learning and development. Englewood Cliffs: Prentice Hall.

Kolts, R. L. (2016). CFT made simple: A clinician's guide to practicing compassion-focused therapy. Oakland: New Harbinger Publications.

Kross, E., \& Grossmann, I. (2012). Boosting wisdom: Distance from the self enhances wise reasoning, attitudes, and behavior. J Exp Psychol Gen, 141, 43-48.

Kunzmann, U., \& Baltes, P. B. (2005). The psychology of wisdom: Theoretical and empirical challenges. In R. J. Sternberg \& J. Jordan (Eds.), A handbook of wisdom: Psychological perspectives (pp. 110-135). New York: Cambridge University Press.

Litz, B. T., Lebowitz, L., Gray, M. J., \& Nash, W. P. (2016). Adaptive disclosure: A new treatment for military trauma, loss, and moral injury. New York: Guilford.

Litz, B. T., Stein, N., Delaney, E., Lebowitz, L., Nash, W. P., Silva, C., et al. (2009). Moral injury and moral repair in war veterans: A preliminary model and intervention strategy. Clin Psychol Rev, 29, 695-706.

Lopez, S. J., \& Snyder, C. R. (2009). Oxford handbook of positive psychology. New York: Oxford University Press.

Louis, M. C., \& Lopez, S. J. (2014). Strengths interventions: Current progress and future directions. In A. C. Parks \& S. M. Schueller (Eds.), The Wiley Blackwell handbook of positive psychological interventions (pp. 66-89). Chichester: John Wiley and Sons.

Loveday, P. M., Lovell, G. P., \& Jones, C. M. (2018). The best possible selves intervention: A review of the literature to evaluate efficacy and guide future research. J Happiness Stud, 19, 607-628.

Macaskill, A., \& Denovan, A. (2014). Assessing psychological health: The contribution of psychological strengths. Br J Guid Couns, 42, 320-337.

Magyar-Moe, J. L. (2014). Applications of positive psychology to individual therapy. In A. C. Parks \& S. M. Schueller (Eds.), The Wiley Blackwell handbook of positive psychological interventions (pp. 255-285). Chichester: John Wiley and Sons.

Meevissen, Y. M. C., Peters, M. L., \& Alberts, H. J. E. M. (2011). Become more optimistic by imagining a best possible self: Effects of a two week intervention. J Behav Ther Exp Psychiatry, 42, 371-378.

Meyer, P. S., Johnson, D. P., Parks, A., Iwanski, C., \& Penn, D. L. (2012). Positive living: A pilot study of group positive psychotherapy for people with schizophrenia. J Posit Psychol, 7, 239-248.

Michalak, J., Mischnat, J., \& Teismann, T. (2014). Sitting posture makes a difference-embodiment effects on depressive memory bias. Clinical Psychology and Psychotherapy, 21, 519-524.

Mongrain, M., \& Anselmo-Matthews, T. (2012). Do positive psychology exercises work? A replication of Seligman et al. (2005). J Clin Psychol, 68, 382-389. 
Moreno, J. L. (1987). The essential Moreno: Writings on psychodrama, group method and spontaneity. New York: Springer.

Orkibi, H. (2019). Positive psychodrama: A framework for practice and research. Arts Psychother, 66, 101603

Orkibi, H., \& Feniger-Schaal, R. (2019). Integrative systematic review of psychodrama psychotherapy research: Trends and methodological implications. PLoS One, 14, e0212575.

Owen-Pugh, V., \& Symons, C. (2013). Roth and Pilling's competence framework for clinical supervision: How generalisable is it? Couns Psychother Res, 13, 126-135.

Owens, R. L., \& Patterson, M. M. (2013). Positive psychological interventions for children: A comparison of gratitude and best possible selves approaches. The Journal of Genetic Psychology: Research and Theory on Human Development, 174, 403-428.

Padesky, C. A. (1990). Schema as self-prejudice. Int Cognit Ther Newsl, 6, 6-7.

Padesky, C. A., \& Mooney, K. A. (2012). Strengths-based cognitive behavioural therapy: A four-step model to build resilience. Clinical Psychology and Psychotherapy, 19, 283-290.

Parks, A. C., \& Schueller, S. M. (2014). Positive psychological interventions. In A. C. Parks \& S. M. Schueller (Eds.), The Wiley Blackwell handbook of positive psychological interventions (pp. 305-320). Chichester: John Wiley and Sons.

Pennebaker, J. W., \& Smyth, J. M. (2016). Opening up by writing it down: How expressive writing improves health and eases emotional pain. New York: Guilford Press.

Perls, F. (1969). Gestalt therapy verbatim. Gouldsboro: Gestalt Journal Press.

Polster, E. (1987). Every person's life is worth a story. Highland: Gestalt Journal Press.

Pos, A. E., \& Greenberg, L. S. (2012). Organizing awareness and increasing emotion regulation: Revising chair work in emotion-focused therapy for borderline personality disorder. J Personal Disord, 26, 84 107.

Pugh, M. (2019a). Cognitive Behavioural Chairwork: Distinctive features. Oxon: Routledge.

Pugh, M. (2019b). A little less talk, a little more action: A dialogical approach to cognitive therapy. The Cognitive Behavioural Therapist, 12, 1-24.

Pugh, M., \& Bell, T. (2020). Process-based chairwork: Applications and innovations in the time of COVID19. European Journal of Counselling Theory, Research, and Practice, 4, 1-8.

Pugh, M., \& Bell, T. (in press). Delivering tele-chairwork: A qualitative survey of expert therapists. Psychother Res.

Pugh, M., \& Broome, N. (2020). Dialogical coaching: An experiential approach to personal and professional development. Consulting Psychology Journal: Practice and Research, 7, 223-241.

Pugh, M., \& Salter, C. (2018). Motivational chairwork: An experiential approach to resolving ambivalence. European Journal of Counselling Theory, Research and Practice, 2, 1-15.

Rashid, T. (2009). Positive interventions in clinical practice. J Clin Psychol, 65, 461-466.

Rashid, T., \& Seligman, M. (2018a). Positive psychotherapy: Workbook. New York: Oxford University Press.

Rashid, T., \& Seligman, M. P. (2018b). Positive psychotherapy: Clinician manual. New York: Oxford University Press.

Rashid, T., Summers, R. F., \& Seligman, M. E. (2015). Positive psychology. Psychiatry, 1, 489-498.

Richards, R. (2010). Everyday creativity: Process and way of life - Four key issues. In J.C. Kaufman \& R.J Sternberg (Eds.), The Cambridge Handbook of Creativity (pp. 180-125_. New York: Cambridge University press.

Schrank, B., Brownell, T., Jakaite, Z., Larkin, C., Pesola, F., Riches, S., Tylee, A., \& Slade, M. (2016). Evaluation of a positive psychotherapy group intervention for people with psychosis: Pilot randomised controlled trial. Epidemiology and Psychiatric Sciences, 25, 235-246.

Schutte, N. S., \& Malouff, J. M. (2019). The impact of signature character strengths interventions: A metaanalysis. J Happiness Stud, 20, 1179-1196.

Seligman, M. E. P. (2002). Authentic happiness: Using the new positive psychology to realize your potential for lasting fulfillment. New York: Free Press.

Seligman, M. E. P. (2006). Afterword: Breaking the 65 percent barrier. In M. C. I. S Csikszentmihalyi (Ed.), A life worth living: Contribution to positive psychology (pp. 230-236). New York, NY: Oxford University Press.

Seligman, M. E. P., Steen, T. A., Park, N., \& Peterson, C. (2005). Positive psychology progress: Empirical validation of interventions. Am Psychol, 60, 401-421.

Seligman, M. E. P., Rashid, T., \& Parks, A. C. (2006). Positive psychotherapy. Am Psychol, 61, 774-788.

Shay, J. (2011). Casualties. Doedalus: The Journal of the American Academy of Arts and Sciences, 140, 180188. 
Sin, N. L., \& Lyubomirsky, S. (2009). Enhancing well-being and alleviating depressive symptoms with positive psychology interventions: A practice-friendly meta- analysis. J Clin Psychol, 65, 467-487.

Stange, A., \& Kunzmann, U. (2008). Fostering wisdom: A psychological perspective. In M. Ferrari \& G. Potworowski (Eds.), Teaching for wisdom: Cross-cultural perspectives on fostering wisdom (pp. 23-36). Burlington: Springer.

Stone, H., \& Stone, S. (1989). Embracing our selves: The voice dialogue manual. Novato: Nataraj Publishing.

Tangden, J. L., \& Borders, L. D. (2017). Applying information processing theory to supervision: An initial exploration. Couns Educ Superv, 56, 98-111.

Tangey, J. P., Boone, A. L., \& Dearing, R. (2005). Forgiving the self: Conceptual issues and empirical findings. In E. L. Worthington Jnr (Ed.), Handbook of forgiveness (pp. 143-158). New York: Routledge.

Teasdale, J. D. (1993). Emotion and two kinds of meaning: Cognitive therapy and applied cognitive science. Behav Res Ther, 3, 339-354.

Teasdale, J. D. (1997). Clinically relevant theory: Integrating clinical insight with cognitive science. In P. M. Salkovskis (Ed.), Frontiers of Congitive therapy (pp. 26-47). New York: Guilford Press.

Tedeschi, R. G., Shakespeare-Finch, J., Taku, K., \& Calhoun, L. G. (2018). Posttraumatic growth: Theory, research, and applications. New York: Routledge.

Teding van Berkhout, E., \& Malouff, J. M. (2016). The efficacy of empathy training: A meta-analysis of randomized controlled trials. J Couns Psychol, 63, 1-10.

Tennen, H., \& Affleck, G. (2002). Benefit-finding and benefit-reminding. In C. R. Snyder \& S. J. Lopez (Eds.), Handbook of positive psychology (pp. 584-597). New York: Oxford University Press.

Tomasulo, D. (2018). Beautiful thinking in action: Positive psychology, psychodrama, and positive psychotherapy. The Journal of Psychodrama, Sociometry, and Group Psychotherapy, 66, 49-67.

Tomasolu, D. J. (2019). The virtual gratitude visit (VGV): Using psychodrama and role-playing as a positive intervention. In L. E. van Zyl \& S. Rothmann Sr. (Eds.), Positive psychological intervention design and protocols for multi-cultural contexts (pp. 405-413). Cham: Springer.

Uliaszek, A. A., Rashid, T., Williams, G. E., \& Gulamani, T. (2016). Group therapy for university students: A randomized control trial of dialectical behavior therapy and positive psychotherapy. Behav Res Ther, 77, 78-85.

Vos, J. (2016). Working with meaning in life in mental health care: A systematic literature review of the practices and effectiveness of meaning-centred therapies. In P. Russo-Netzer, S. E. Schulenberg, \& A. Batthany (Eds.), Clinical perspectives on meaning: Positive and existential psychotherapy (pp. 59-87). Cham: Springer.

Wade, N. G., \& Worthington Jnr., E. L. (2005). In search of a common core: A content analysis of interventions to promote forgiveness. Psychother Theory Res Pract Train, 42, 160-177.

Wells, J. (2018). Psychodramatic resiliency timeline. The Journal of Psychodrama, Sociometry, and Group Psychotherapy, 66, 131-140.

Whelton, W. J. (2004). Emotional processes in psychotherapy: Evidence across therapeutic modalities. Clinical Psychology and Psychotherapy, 11, 58-71.

White, C. A., Uttl, B., \& Holder, M. D. (2019). Meta-analyses of positive psychology interventions: The effects are much smaller than previously reported. PLoS One, 14, e0216588.

Wong, P. T. P. (1998). Spirituality, meaning, and successful aging. In P. T. P. Wong \& P. S. Fry (Eds.), The human quest for meaning: Theories, research, and applications (1st ed., pp. 359-394). Mahwah: Lawrence Erlbaum.

Wong, P. T. P. (2012). The human quest for meaning: Theories, research, and applications (2nd ed.). New York: Routledge.

Wood, A. M., Froh, J. J., \& Geraghty, A. W. (2010). Gratitude and well-being: A review and theoretical integration. Clin Psychol Rev, 30, 890-905.

Wood, A. M., Maltby, J., Gillett, R., Linley, P. A., \& Joseph, S. (2008). The role of gratitude in the development of social support, stress, and depression: Two longitudinal studies. J Res Pers, 42, 854-871.

Worthington Jr., E. L. (2006). Forgiveness and reconciliation: Theory and application. New York: Routledge.

Worthington Jr., E. L., Wade, N. G., \& Hoyt, W. T. (2014). Positive psychological interventions for promoting forgiveness: History, present status, and future prospects. In A. C. Parks \& S. M. Schueller (Eds.), The Wiley Blackwell handbook of positive psychological interventions (pp. 20-41). Chichester, West Sussex: John Wiley and Sons.

Yalom, I. D. (1980). Existential psychotherapy. New York: Basic Books.

Yaniv, D. (2012). Dynamics of creativity and empathy in role reversal: Contributions from neuroscience. Rev Gen Psychol, 16, 70-77.

Yardely-Matwiejczuk, K. M. (1997). Role play: Theory and practice. London: Sage.

Publisher's Note Springer Nature remains neutral with regard to jurisdictional claims in published maps and institutional affiliations. 